\title{
A Comparative Study of WH-Movement in Urdu and English: A Minimalist Perspective
}

\author{
Binish Maqsood ${ }^{1}$, Asif Aziz ${ }^{1}$, Tahir Saleem ${ }^{1} \&$ Summiya Azam ${ }^{1}$ \\ ${ }^{1}$ University of Central Punjab, Lahore, Pakistan \\ Correspondence: Summiya Azam, University of Central Punjab, Lahore, Pakistan. E-mail: \\ summiyatahir@yahoo.com
}

Received: April 6, 2018 Accepted: July 19, 2018 Online Published: September 1, 2018

doi:10.5539/ijel.v8n6p203 URL: https://doi.org/10.5539/ijel.v8n6p203

\begin{abstract}
The present study aims at presenting a comparative study of Urdu and English in terms of Wh-movement in the light of the minimalist program (MP) as the theoretical framework of the study. For this purpose, Urdu and English data related to Wh-expressions is used. The empirical evaluation of data reveals that Wh-movement is mandatory in English while, non-mandatory in Urdu. Furthermore, it shows that the movement of tense markers in English is obligatory along with the movement of Wh-phrase as compared to Urdu in which it is optional. The movement of tense markers is covert in Urdu as compared to its overt movement in English. The findings of the study show that the feature of [+WH, EPP] stimulates the movement of Wh-expression in order to check these features. The findings of the study are expected to prove helpful for students and researchers in understanding the nature of syntax in general and Wh-movement particularly.
\end{abstract}

Keywords: Wh-movement, Minimalist Program, mandatory vs non-mandatory, covert and overt movement, Syntax, Urdu and English

\section{Introduction}

All languages are similar and different from each other in a certain respect because all languages are similar in the sense that all are equipped with UG (universal grammar) and it is generalized that there are two contents of UG, Principles, and Parameters (Radford 2004; Kim \& Sells, 2008). Principles are considered universals on the basis of which it is suggested that all languages are similar, while on the other hand, Parameters are regarded as those elements which mark sharp differences between different languages (Miller, 2016; Yeo, 2009; Givon, 2001).

The current research tries to investigate the parametric variation between Urdu and English in terms of Wh-movement. Assuming Minimalist Program proposed by the researcher Rivero (1978), as the method for investigating the comparative nature of Wh-movement (a type of movement operation with the help of which a Wh-expression moved out from its original position towards the fronting position of the sentence) in Urdu and English.

Therefore, the present study focuses on the investigation of Wh-movement between Urdu and English language. Furthermore, it concentrates on investigating how the movement of Wh-expression affects the grammaticality of the sentence and why it is always triggered towards the fronting position of the sentence in English as compared to Urdu. It is hoped that the findings of the present study would prove beneficial for researchers, students, and readers in order to have a better understanding of syntax in general and Wh-movement in particular.

Wh-movement is an operation in syntax by which a Wh-phrase comes out of its latent point in the deep-structure of a sentence which results into the Surface-Structure of the sentence (Principle and parameter approach, Chomsky, 1982). Cook and Newson (2014) argue that "the movement of a Wh-expression states the movement of question component or interrogative phrase from an argument position towards the closest non-argument position which indicates complementiser phrase (Cole \& Hermon, 1994). The term Wh-movement comes from early Generative grammar $(1960,1970)$ in which the major focus about Wh-movement was that Wh-expression (what, which, who, where, why) appeared first in its authoritative position and then by applying the operation Move, it is moved towards the left side, out of its in-situ position, to rest in its derived position which is specified at the beginning of the sentence (Chang, 1997; McCloskey, 2000). 


\subsection{Classification of Wh-movement}

Wh-movement can be classified into following categories on the basis of distance and on the basis of position regarding the application of the movement.

\subsection{Distance-Based Classification}

On the basis of distance, Wh-movement can be classified into followings:

\subsection{Wh-movement with no Distance}

The movement of a Wh-expression in a sentence containing one clause termed as Wh-movement without distance. Such as what are you saying t?

\subsection{Wh-movement Based on Distance}

The movement of a Wh-phrase in a sentence which contains one main clause and two or more subordinate clauses regarded as the Wh-movement with distance. In such types of sentences, a Wh-expression moves from its extracting point of the subordinate clause towards the landing point of the complementiser phrase specifier position of CP of the main clause (Horrocks \& Stavrou, 1987; Simpson \& Bhattacharya, 2003). Wh-movement with distance takes place in a cyclic fashion, e.g. what did you think that he eat $\mathrm{t}$ ?

\subsection{Wh-movement with Multiple Wh-expressions}

There are a number of sentences containing one or more than one Wh-words. The movement of Wh-word in such a sentence based on the Attracts Closest Principle (Dayal, 2017). This principle states, "A head which attracts a given kind of constituent attracts the closest constituent of the relevant kind" e.g. who might he think t has done what? The above example is the s-structure representation of the D-structure of the following sentence; he might think who has done what? Since in the sentence, there are two Wh-words who and what and according to Attract Closest Principle "who" is closer to the main clause than "what", so "who" will move towards the Specifier position in CP of the sentence (Simpson \& Bhattacharya, 2003).

\subsection{Classification on the Basis of the Position of Applying Movement}

On the basis of the position of movement, the movement of Wh-phrase can be observed on the syntactic and semantic level.

\subsection{Movement on a Syntactic Level}

The movement of Wh-word on the syntactic level is applied in the D-structure of the sentence and its representation can be observed at S-structure. Movement in terms of the syntactic level is considered compulsory for the languages which incorporate it. Therefore, if the Wh-expression does not undergo movement from its argument position towards its non-argument position, the resulting structure is considered ungrammatical in nature (Hartmann, 2016).

\subsection{Movement on Semantic Level}

In some languages in which Wh-expression does not move from its authoritative position towards Specifier position of CP, the movement said to take place at the semantic level. In simple terms, according to Simpson and Bhattacharya (2003), such languages are regarded as "Wh-in-situ language, in which movement occurs but not visible at S. structure of the sentence and the movement of Wh-word occurs at logical form (LF) of the language-independent component of human language faculty and used for interrogative purposes (Toosarvandani, 2008). In Government and Binding theory, it is maintained though Wh-phrases do not move in a syntactic part in Wh-in-situ languages, a rule such as Wh-movement in logical form is applied (Manetta, 2010).

In English language, the movement of Wh-expression is considered a syntactic property because it requires the movement to be visible at S-structure in order to form a question, while the syntactic structure of Urdu is different from English (Dayal, 2017). In Urdu, the movement of Wh-word as a rule of transformation is constructed as syntactic meanwhile pragmatic in nature (Manetta, 2010). It is not mandatory for Urdu to show Wh-movement at the syntactic level. Since Urdu is a multidimensional language, therefore, the movement of Wh-expression will be assumed multifunctional. Hence, in this study, the Wh-movement is investigated in both Urdu and English.

In recent years many studies have been conducted on Wh-movement taking into consideration different perspectives. Fakih (2015) in his study on "Wh-questions in Hodeida Arabic: A phase-based approach" tried to provide a satisfactory account of their syntactic behavior in the light of Chomsky's' phase-based approach. He proved that the movement of Wh-expression is obligatory in nature in Hodeida Arabic. He also proved that the movement of Wh-phrase satisfies Noam Chomsky Phase-based approach and Phase-Impenetrability Condition. 
Another study conducted by Bayer (2015) to investigate Wh-in-situ position taken into account different concepts related to Wh-in-situ such as, covert movement and logical form, quantifier raising, and movement, covert movement in Wh-in-situ languages, parallels between Wh-extraction and Wh-in-situ, difference between overt movement in Wh-in-situ, coping, pied-piping, Q-Binding and D-linking. Furthermore, the researcher discussed various accounts of Wh-in-situ in the light of Minimalist theories covering the following perspectives: Feature/particle movement, overt movements, Remnant as a disguise, Pronounce lower Copy, No movement, and Wh-in-situ or Wh-ex-situ etc. The researcher also discussed non-syntactic treatments of intervention effects including movement versus in situ position of Wh-expressions.

Mowarin and Oduaran (2014) in their study, "A contrastive Inquiry into Wh-interrogatives in English and Nigerian Pidgin" took Noam Chomsky's Minimalist Program of transformational grammar as the theoretical framework, to investigate the Wh-interrogatives movement. They used a pedagogical approach for the study. In their study, they studied English and Nigerian Pidgin and cross-linguistic typological variations of Wh-questions, the Wh-interrogatives in English and Nigerian Pidgin with focus on Wh-word and phrases, movement, pied-piping and constraints on Wh-movement in two languages including the learning problems that a competent speaker of Nigerian pidgin encountered. The findings of their study illustrated that the problems of language deficit in English faced by Nigerian students can be reduced if English as the second language was taught by contrastive methods of teaching. Abedi, Moinzadeh, and Gharaei (2012) conducted their study "the movement of Wh-expression in English and Persian in the light of the framework of GBT"'. They did a comparative study of movement in terms of Wh-expression. For this purpose, they employed Chomsky's GB (1982) theory as the theoretical framework of their study. On the basis of the analysis, the researchers concluded that the English language has similarity in terms of the application of Wh-movement with the Persian language. Among the similarities, certain concepts such as theta criterion, case generator and case filter principle over Wh-expression were noted. In terms of differences between the syntactic categories of two languages, certain aspects were analyzed such as:

- Obligatory nature of Wh-movement rule in English Vs its non-mandatory rule in Persian.

- Syntactic Vs non-syntactic movement of Wh-expression in English is in contrast with Persian.

- Syntactic trigger Vs pragmatic trigger in English as opposed to Persian.

- The fixed syntactic position of $\mathrm{CP}$ for Wh-expression as opposed to a different position for Wh-word in English and Persian respectively.

Malhotra (2009) investigated "Intervention Effect and Wh-movement" in which the researcher argued that intervention effects are visible in many natural languages, which has become a debatable issue in the semantic and syntactic literature in the last decades. In the current study, the researcher tried to highlight the limitations in the earlier proposed model about intervention effects and WH-movement in order to propose a reanalysis of intervention effects in terms of head-moved. The paper also provided an alternative Wh-movement approach for some languages that show intervention effect in respect of Wh-in-situ languages. The researcher also claimed that the nature of Wh-movement in natural languages has a direct consequence on the nature of Wh-quantifier interactions. For the purpose of achieving the objectives of the study, the researcher examined data from different languages particularly Hindi, English, and Chinese so that the nature of Wh-movement in these languages can be used to predict the intervention as well as Island effects. In a similar vein, Al-Touny (2011) investigated the formation of questions in English and Cairene Arabic under the framework of Minimalist Program and optimality theory which consider the formation of high-ranked constraints in a typology that is language particular. Abu-Jarad (2008) studied a typology of Wh-movement in his study "Wh-movement in Palestinian Arabic". Findings illustrated that Wh-operators perform two functions in Palestinian Arabic on the basis of the type of Wh-operator either it is Wh-argument or it is a Wh-adjunct. In this paper, he supported his argument "Wh-adjuncts undergo syntactic movement, while Wh-argument do not undergo" in light of Wabha (1992) and Cheng (2000) proposed works. Cheng's (1997) studied "Partial Wh-movement" re-examined the notion of Wh-movement in terms of its partial movement. Partial Wh-movement refers to a type of movement which possess the following characteristics;

1) A Wh-word is moved "half-way", landing at a Spec position of $\mathrm{CP}$ which is not associated with the scope of the Wh-word.

2) A scope marker appears at the $\mathrm{CP}$ where the Wh-word is interpreted as taking a scope.

To come up with appropriate findings, the researcher employed the Minimalist Program as the theoretical framework of his study. He suggested that partial Wh-movement involves the overt movement of part of a 
Wh-word (i.e. partial), namely the Wh-feature of a Wh-word. On the basis of this suggestion, the researcher tried to show that the feature movement can provide some sort of natural expectations to question raised due to the phenomena of partial Wh-movement. For this purpose, the researcher comparatively analyzed partial movement involved in German and Hindi and reached a the conclusion that in later language (Hindi) partial Wh-movement did not involve overt feature movement. It can be seen from above-mentioned studies that no study is conducted as far the Urdu language is concerned. Therefore, the present study would be of considerable importance because it aimed at the comparative study of Wh-movement in English and Urdu within the Minimalist Program (Chomsky, 1995). The study would weigh great significance because it is syntactic in nature and if we look in Pakistani context there are few studies conducted in this particular context (syntax) or if any, in those studies no attempt was made to study the comparative nature of Urdu and English in spite of the fact that these two languages are regarded as echo languages to one another. The application of Chomskyian syntactic theory of MP seemed rare in Pakistani context especially in case of Urdu language, due to which it is hoped that the study could enjoy good repute by bringing into the limelight this particular phenomenon. The current study would be of exceptional importance because it focusses on providing subsidiary literature related to the phenomena of movement of Wh-expression in English as well as in the Urdu language as compared to other studies carried out at the nominated issue in particular. Furthermore, the present work would help the researcher and reader in the general understanding of the Chomsky's Principle and Parameter approach (1981) towards the study of syntax. It is hoped that the findings of the current study will be fruitful in resolving the controversy about the status of Urdu in terms of head-final or head-initial language.

\section{Urdu Wh-expressions and Minimalism}

Chomsky's Minimalist Program was used as the method of the present study because it was used by the researcher as the theoretical background for this study. Chomsky worked over many years and provided multiple ideas that are considered central to the study of linguistics and syntax. Chomsky's ideas that are central to the study of syntax are collectively known as Minimalist Program which he has presented in linguistics since 1993. It was found that Chomsky's earlier work in the development of linguistic theory draws it's over complex picture by presenting a complex grammatical apparatus for the generation of well-formed derivations.

However, since 1993, his syntactic ideas presented in linguistics are considered as an attempt to minimize the theoretical and descriptive apparatus that are employed to account for the potential of monolingual speaker producing an infinite number of well-formed grammatical constructions. As a matter of fact, the central purpose of MP is the exclusion of all mechanisms that are not necessary on conceptual grounds.

In simpler terms, MP tries to provide an explanation of monolingual linguistic competence (MLC) which enables them to generate an infinite number of sentences which are grammatical in nature and considered as the expressions of one and only one grammar of a specific language. According to Seuren (2004), MP is comprised of two basic ideas. The central concept to the first idea is Principle and Parameter which are considered responsible for similarities and differences among different language pairs.

Hence, all languages are similar in this respect that they all share the same fundamental principles, while differences are due to parameters because parameter setting varies across the languages due to which differences are predictable. The second idea proposed is that universal machinery should be seen in the perspective of the technical problem of how best to link up the propositional thought with sound (Seuren, 2004, p.5). However, the MP cannot be taken as a "Unified Theory of Language" (Cook and Newson, 2014, p. 242).

MP takes syntax as a cognitive system by rejecting the concepts of S-Structure and D-Structure of the Government and Binding theory proposed in 1982 (Chomsky, 1982). Syntax as a cognitive system in the light of MP connects with other two cognitive systems named as Articulatory-Perceptual (A-P) and Conceptual-Intentional (C-I) system. According to Chomsky (1995), it becomes compulsory for a syntactic model to bring into limelight the interface levels where it may interact with the A-P and C-I systems for the purpose of converting linguistic properties into signals to the brain for producing and interpreting language.

Similarly, such modular interfaces are recognized in MP as Logic form (which is used for the interpretation of language) and Phonetic form for the production of language (Chomsky, N. 1995). Distinct from Government and Binding theory that is applied at different levels of representation as for the grammaticality of a sentence is concerned, the conditions of grammaticality here are applicable on two levels of interfaces such as PF and LF in MP (Chomsky, 1995).

These two interfaces perform their function in connecting faculty of human language (FL) to two cognitive systems named A-P and C-I. If we talk about the design of the FL in MP it consists of two parts. One is a language-specific component and other is language independent component. The language-independent 
component named as "Computational system of human language", has a different number of subsystems which operate on lexical items taken from the lexicon in order to form an infinite number of sentences, which are well-formed and grammatical in nature.

For the purpose of the derivation of a well-formed expression in first place, numeration is created by an Operation Select including the information such as a number of selected lexical items and how many times these items will be repeated in the derivation. After the selection of lexical items from numeration, the operation Merge operates, in order to structures the LIs into complex objects hierarchically on the basis of a set of features specified by syntactic objects available in numeration. After this, as mentioned by Zeljko (1999), the arranged syntactical derivation sends towards further Operation named Spell-out, where the derivation splits into two and sends it for interpretation to both interfaces. At the spell-out, the elements that are relevant only to the PF are stripped away while the remainder is continued computation to the LF (Chomsky, 1995).

The operation Merge and Move are different from each other in respect of what they take to merge. Merge operation merges the LIs contained in a syntactic derivation while the Move Operation applies to remerge the merged items according to the requirement of syntactic derivation. In simple terms merge constructs something new out of the items available in numeration taken from the lexicon, while the move is applied to make amendment in the syntactic objects in order to meet the grammatical requirement of the derivation.

According to Chomsky (1995), application of the Merge and Select operation is "costless" because if the features of syntactic objects are not compatible then derivation is canceled which results in no additional cost. While on the other hand, the application of Move is not "costless" and incurs a derivational cost. The movement of items in order to justify different requirements results in extra derivational cost.

If one talks about the movement, he(s) may encounter two different types of movements i.e. Head Movement and XP movement. In head movement, a head leaves its place and joins to another head in the derivation. While in XP movement, the maximal projection triggered out from its base position in order to take another place so that its features can be checked because it is a set pre-condition of Principle of Full Interpretation, that is, un-interpretable features should be checked/valued against the interpretable features.

Feature valuation is a pre-condition for a well-formed grammatical expression because the existence of such features transfers illegible material to the interface PF and LF, which ultimately results in a crash. The principle of Full Interpretation posits constraints on the formation of the well-formed grammatical sentence which stipulates that every element of the representation must have a language-independent interpretation and a derivation is said to be convergent only if it transfers information which is legible at the PF and Lf interfaces (Chomsky, 1995).

The other component of the language faculty is a language-specific L (Lexicon). L consists of an array of syntactic learned items, which have different categorical status on the basis of features which they possess. The features on the basis of which lexical items are differentiated are of two major types i.e. Lexical categorical (LC) features and functional (F) features. The F-features associated with functional categories are checked against the LC features of the syntactic categories by applying Move operation. If one compares both components of language faculty will come to know that L consists of LIs which carry language-specific information in the form of morphological features and the other component is said to be universally invariant across different human languages and speakers.

\section{Description of Urdu Wh-phrases}

In order to describe how Wh-movement operates in English, and how it is linked with Urdu, has been discussed in this section while taking examples from English. Consider the following examples:

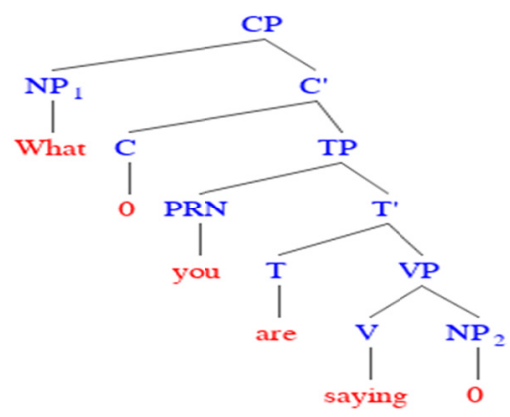

Figure 1. Syntactic movement of Wh-expression 
In this example, we can see the exact place of auxiliary "are" before it is raised at the level of complementiser, as can be seen in the next example.

1 (a) what are you saying t?

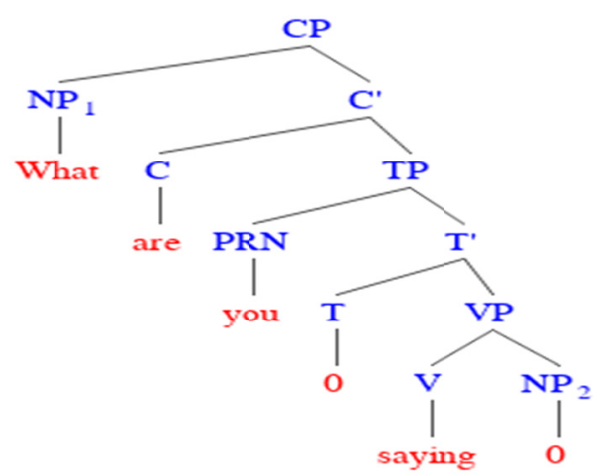

Figure 2. Syntactic movement of Wh-expression

In this example, the Wh-word "what" merges with the verb "saying" to form VP saying what, which further merges with the present tense auxiliary "are" to form T-bar [are saying what], which in turn merges with the pronoun [You] in order to form TP [You are saying what]. Since the present tense auxiliary "are" have the features of tense marker $[+\mathrm{WH}]$ that it can be used to form an interrogative sentence and also equipped with EEP feature which suggests that it can be moved to the interrogative $\mathrm{C}$ position of $\mathrm{CP}$. Furthermore, it is claimed that the [EPP, $+\mathrm{WH}$ ] features of $\mathrm{C}$ requires that $\mathrm{C}$ should have a Wh-expression at the specifier position of $\mathrm{CP}$. Now consider this example in Urdu language

1(b) Kaya keh rhy ho tum t?

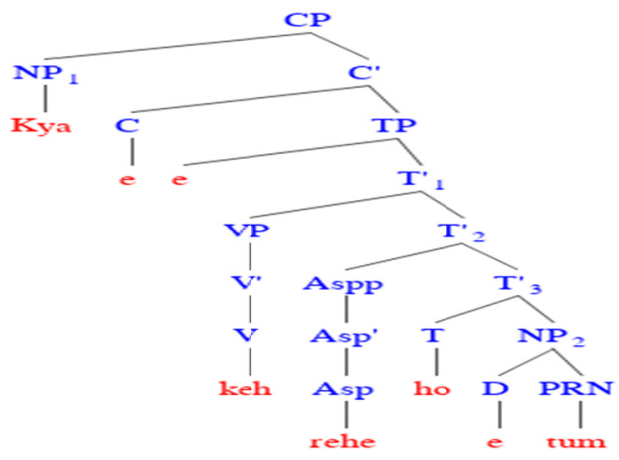

Figure 3. Syntactic movement of Wh-expression

(c) Tum kaya keh rhy ho t?

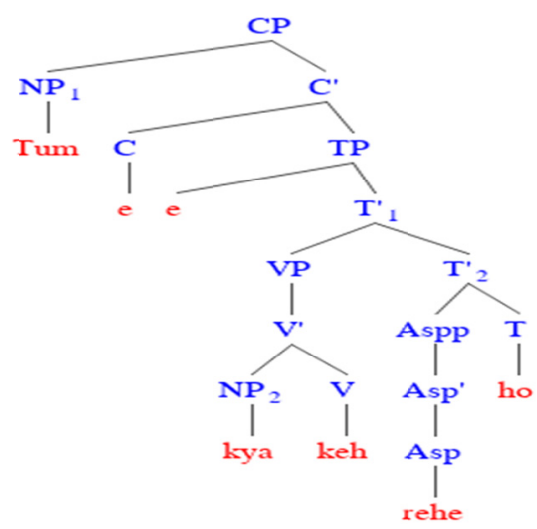

Figure 4. Syntactic movement of Wh-expression 
(d) Tum keh rhy ho kaya?

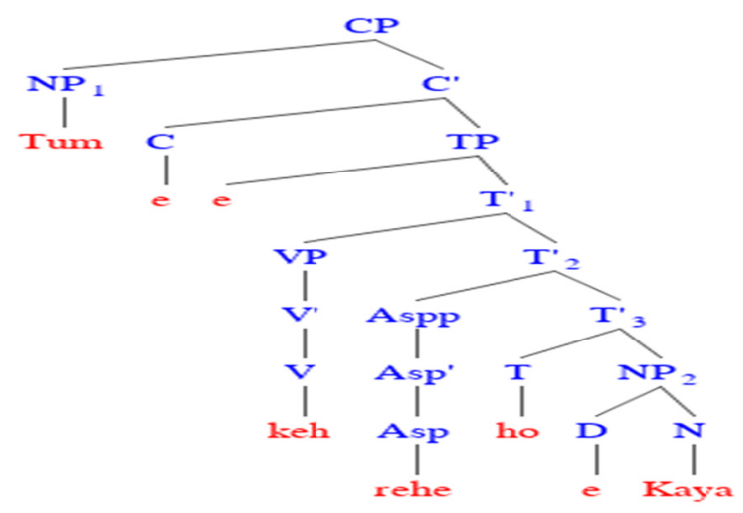

Figure 5. Syntactic movement of Wh-expression

In these sentences [(b), (c) \& (d)] the Wh-phrase "Kaya" in Urdu language occupies three different positions in order to make the sentence interrogative. In 1(b) the word "kaya" merges with the verb "keh" in Urdu to form VP, which further merges with the present tense auxiliary "rhy ho" to form T-bar, which in turn merges with the pronoun "tum" to form TP. In English language whenever the movement of Wh-phrase takes place, it will always attract the auxiliary verb because it contains the [TN's, EPP, +WH] features which require that it should move towards the $\mathrm{C}$ position of $\mathrm{CP}$ and $\mathrm{C}$ requires that a Wh-phrase should be at specifier position of $\mathrm{CP}$ but the case in Urdu language is different, here a null-complementizer is introduced because the movement takes place covertly as compared to the overt movement of auxiliary in English. Because in Urdu sometimes auxiliaries are attached with the verb itself and if we move Wh-expression in Urdu, it is not obligatory that it attracts the auxiliary towards the $\mathrm{C}$ position of CP. Therefore, in order to make the derivation of a sentence successful, a null complementizer is introduced in Urdu, which merges with the moved Wh-expression "kaya" to CP having "kaya" at specifier position of CP.

In other sentences of 1 (b) and (c) the Wh-phrase "kaya" occupies two different positions retaining the grammaticality of the sentence. In Urdu, the Wh-expression equivalent words occupy both in-situ and moved position as compared to English. In the sentence "Tum keh rhy ho kaya', it remains in its in-situ position but in its derivational process, its movement is also illustrated in the formation of CP as explained above, while in the sentence "Tum kaya keh rhy ho t?" the phrase kaya is moved from its original position towards the C position of $\mathrm{CP}$ because it possesses [ $+\mathrm{WH}]$ feature due to which it can be moved from its latent location towards $\mathrm{C}$ position in order to form $\mathrm{CP}$ giving interrogative sense to the sentence.

Our next objective of the current study deals with the effects of movement of Wh-expression on the grammaticality of the sentence. In order to illustrate the effects of Wh-movement on the grammaticality of sentence, consider the following examples:

2 (a) what does Ali know it?

In this sentence the Wh-word "what" moves out from its original position "Ali knows what?" towards the beginning of the sentence but if we move it to another position instead of beginning, does it affect the grammaticality of the sentence, because in the light of Chomsky's MP (Minimalist Program) as the theoretical framework of the study, each and every sentence ever produced by human beings of a particular language should be grammatical. Let's see what happens at the movement of Wh-phrase at different positions as:

2 (b) what does Ali know it?

(c) *Ali knows what?

(d)*Ali what knows t?

(e)* Does Ali what know it?

As mentioned above, the sentence (b) is grammatical in nature, when a Wh-expression moves out from its original position towards the beginning of the sentence but when it moves from its original position towards the middle or at the end of the sentence then its movement effects the grammaticality of the sentence due to which sentence becomes ungrammatical. But in accordance with MP, no grammatical sentence can be produced due to which it is 
mandatory in English that Wh-phrase should be placed at the beginning of the sentence as far the notion of grammaticality is concerned. But in Urdu, the case is different, the Wh-phrases (kaya, kahan etc.) occupy different positions in the sentences and it does not affect the grammaticality of the sentence such as:

3 (a) Ali kaya janta hy t?

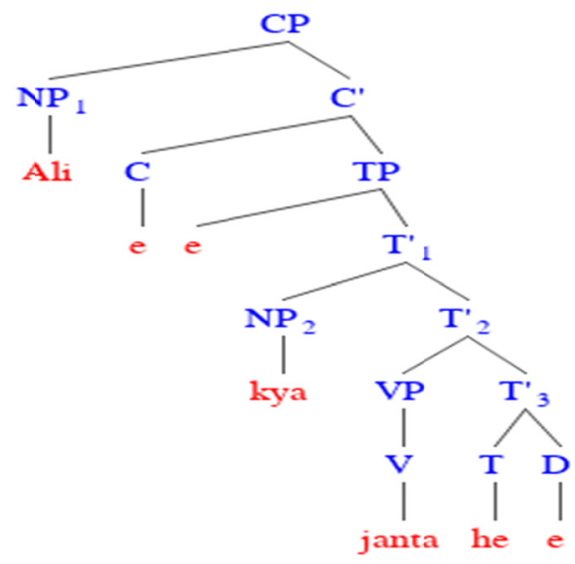

Figure 6. Syntactic movement of Wh-expression

(b) Ali janta hy kaya?

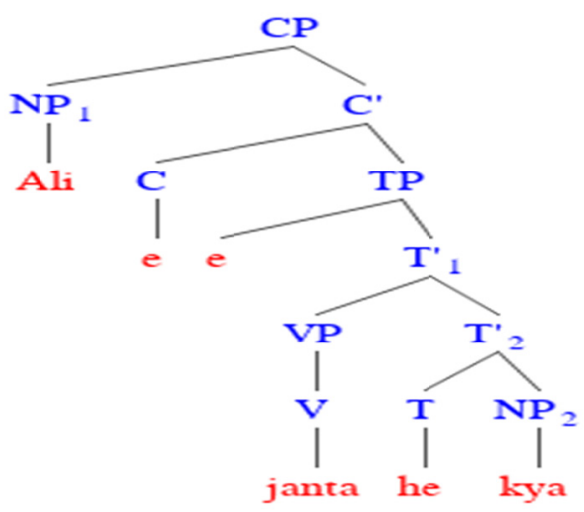

Figure 7. Syntactic movement of Wh-expression

(c) Kaya Ali janta hy?

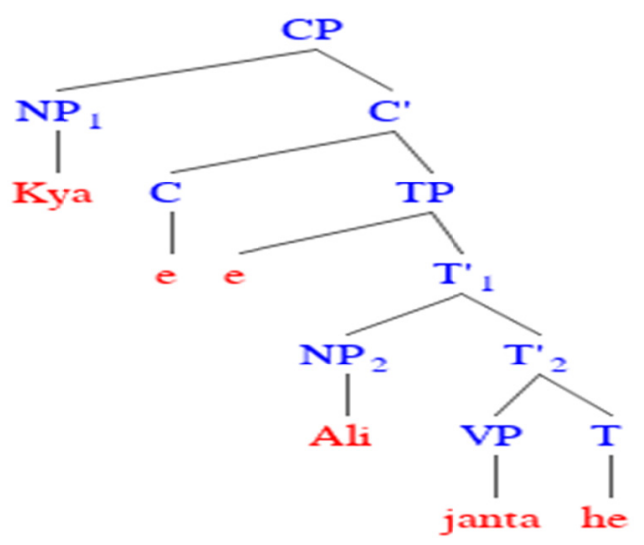

Figure 8. Syntactic Movement of Wh-expression 
(d) Janta hy kaya Ali?

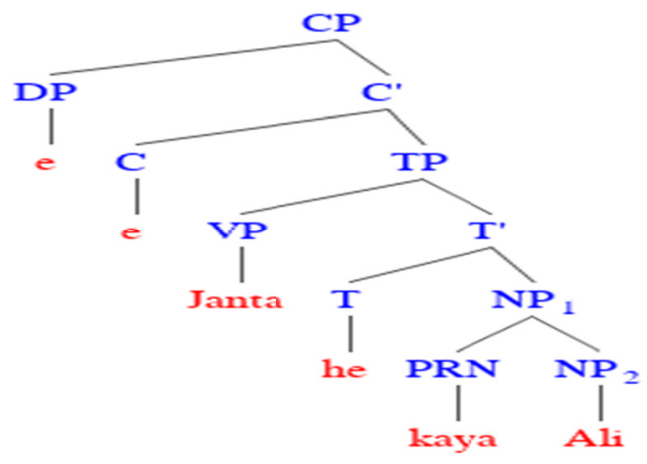

Figure 9. Syntactic Movement of Wh-expression

As shown above in [(a), (b), (c) \& (d)] the phrase "kaya" as a Wh-phrase occupies different positions in each sentence and all sentences are grammatical in nature. So, it can be argued that in Urdu the movement of Wh-phrase is regarded as non-mandatory which shows that it is not obligatory that Wh-phrase should come always at the beginning of the sentence in order to retain the grammaticality of the sentence. It can come at the beginning, middle and at the end of a sentence and grammaticality of a sentence is not affected.

Our third stance deals with the trigger of Wh-expression which can be explained as Chomsky believes that any movement in order to call syntactic process should be equipped with the stimulus that stimulates it to undergo different movement. Therefore, it is assumed that there are certain features that stimulate the movement of Wh-phrase in a sentence. Chomsky $(1998,1999,2001)$ proposes that EPP feature triggers the movement of a Wh- phrase to Spec-CP. To be more precise, he advocates that as T carries an [EPP] feature which requires it to be moved into a TP projection having a subject specifier, in the same way, $\mathrm{C}$ too in Wh-question carries an [EPP] feature which demands it to be extended into a CP containing Wh-phrase as its specifier. Along with the EPP feature, Chomsky maintains that the feature which is considered responsible for the movement of Wh-phrase is the interrogative characteristics, which is denoted by $[+\mathrm{WH}]$ and this characteristic exists in the location of $\mathrm{C}$ of an interrogative sentence which contains Wh-phrase. Therefore, the Wh-phrase moves towards the specifier position of $\mathrm{CP}$ in order to match the $[+\mathrm{WH}]$ feature. According to Carnie $(2002$, p. 2850), the interrogative phrase [Wh-expression] moves toward the non-argument position in order to evaluate the interrogative feature [ $\mathrm{WH}]$.

\section{Wh-movement in English}

The term movement is also regarded as another form of "merge" with a slight difference. In merge operation, the operations take into account the selection of lexical items and merging them with each other in the syntactic structure, while move operation involves the re-arranging of the syntactic constituents according to the requirement of sentence or in simpler terms to match the corresponding features of the constituents in order to maintain the grammaticality of derived expression. The movement in terms of Wh-movement varies across languages. As discussed above, the nature of Wh-expression should be moved towards the beginning of the sentence and non-mandatory in Urdu as evident from the above-illustrated examples which show that it can occupy different positions to form interrogative sentences. The WH-movement highlights sharp differences in its application both in English and Urdu. In English when/WH-movement occurs, it will always attract the acicular verb towards the $\mathrm{C}$ position of $\mathrm{CP}$ having WH-phrase at the specifier position in order to construct a perfect $\mathrm{CP}$ as shown in the following figure: 
(a) What are you saying?

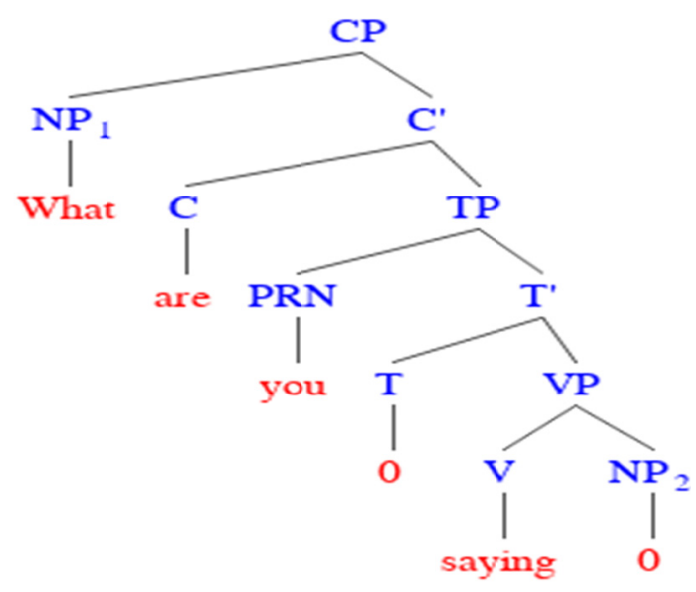

Figure 10. Syntactic Movement of Wh-expression

In the above figure, the auxiliary verb moves from its tense position towards the $\mathrm{C}$ position of $\mathrm{CP}$ in order to form $\mathrm{C}$-bar having a Wh-expression at the specifier position to form CP. While in Urdu auxiliary verbs are not attracted towards the $\mathrm{C}$ position of $\mathrm{CP}$ because it is not obligatory that it should move towards this position. In Urdu, a null complementiser is introduced at $\mathrm{C}$ position of $\mathrm{CP}$ instead of an auxiliary verb as shown in the figure 6,7 , and 9 in section 3 .

(b) What you are saying?

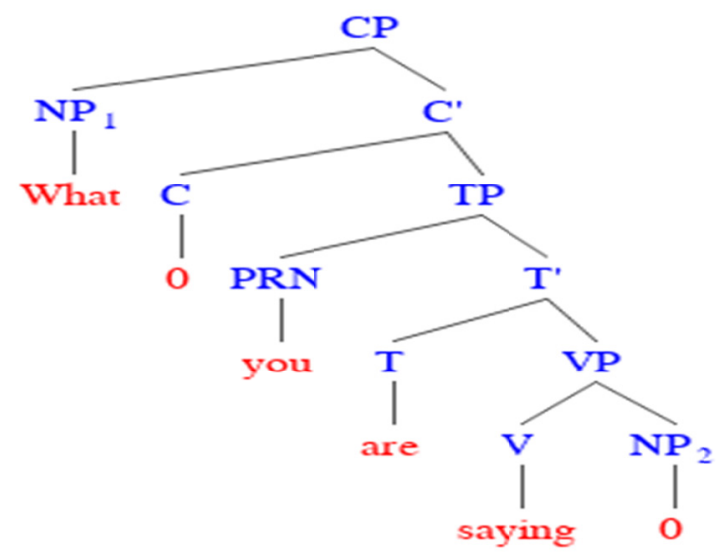

Figure 11. Syntactic Movement of Wh-expression

The movement of WH-phrases shows the application of C-command principle which is observable in the merge operation because the lexical constituents merge with each other in order to construct a successful tree of the derivation as shown below the WH-phrase moves out from it's argument position I-e space - CP. The extracted WH-phrase shows C-commands over its effect, which can be observed in the lower noun phrase position. The movement of WH-phrase from deep structure towards surface structure does not affect the grammatically of the sentence. 
(c) What does Ali know?

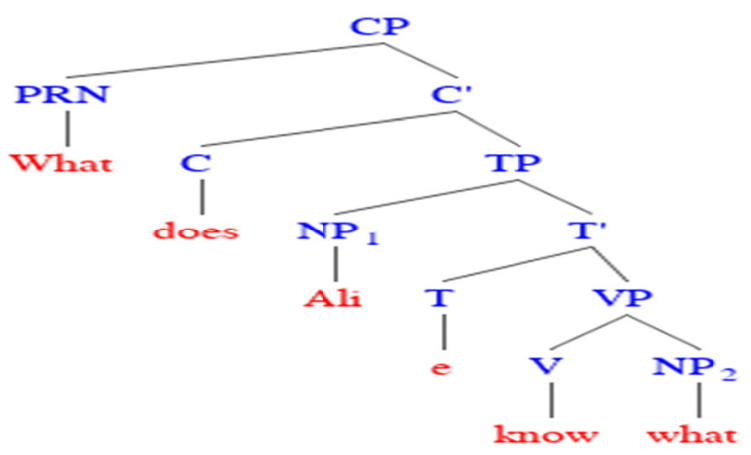

Figure 12. Syntactic movement of wh expression and auxiliary

To sum up, our discussion related to the main concern of this study, we can say that the movement of WH-expression differs in both languages (English and Urdu), the point of sharp differences is given below:

- Mandatory Vs non- mandatory nature of WH-movement

- Movement of the tense marker (auxiliaries) is obligatory along the movement of WH-phrases in the English language

- Movement of the tense marker is optional along the movement of WH-phrases in the Urdu language

- C-command principle is observed in the movement of WH-expression in both language (Urdu and English)

As illustrated above, the movement of wh-expression effects the grammaticality of the sentence but here also both languages are in contrast with each other. In case of English, the moment of Wh-expression is always at the beginning of the sentence in order to make the sentence interrogative and in doing so the grammaticality of the sentence is not affected in line with the basic concept in MP. But if we move a Wh-phrase at the other positions of the sentences then the sentence becomes ungrammatical as shown in example 2[(c), (d) \& (e)] above. But in Urdu, the case is different, which shows that the moment of Wh-phrase does not affect the grammaticality of sentence, which implies that in Urdu language a Wh-phrase can be moved at beginning, middle and ending position of the sentence to perform a single function, which is of making the sense of sentence interrogative. As shown in example $1[(\mathrm{~b}),(\mathrm{c}) \&(\mathrm{~d})]$ the Wh-phrase "kaya" from Urdu is placed at three different positions and all these sentences are grammatical in nature.

Finally, the Wh-phrases are assumed having a certain type of features which demand its movement from its in-situ position towards the moved location in a syntactic derivation. It is argued that Wh-phrases have EPP feature which triggers its movement towards specifier position of CP. To be more precise, it is argued that as $\mathrm{T}$ carries an EPP feature which demands it move into a TP phrase having a subject specifier, in the similar vein, it is assumed that $\mathrm{C}$ to carries an EPP feature which demands it move at $\mathrm{C}$-bar position of $\mathrm{CP}$ having a Wh-phrase equipped with $[+\mathrm{WH}]$ feature at specifier position of CP. Therefore, it is assumed that Wh-phrase moves towards non-argument position $[\mathrm{Spec}-\mathrm{CP}]$ in order to evaluate it $[+\mathrm{WH}]$ feature so that the derivation of a sentence can be carried out.

\section{Conclusion}

In respect of the findings of this study related to the movement of Wh-expression in Urdu and English shows that the movement of Wh-expression varies across both the languages. In English, Wh-phrase always moved towards the beginning of the sentence in order to form an interrogative sentence as compared to Urdu in which this movement takes place in a multidimensional manner. The movement of Wh-expression affects the grammaticality of the sentence in English if it is moved at different positions as compared to Urdu. There are certain features such as the EPP feature and +WH feature, which trigger the movement of Wh-expression.

\section{References}

Abedi, F., Moinzadeh, A., \& Gharaei, Z. (2012). WH-movement in English and Persian within the Framework of Government and Binding Theory. International Journal of Linguistics, 4(3), 419-432. https://doi.org/10.5296/ijl.v4i3.2325 
Abu-Jarad, H. (2008). Wh-movement in Palestinian Arabic. Al-Azhar University Journal Gaza, 10(1), 49-62.

Al-Shorafat, M. (2013). A phase-based account of Wh-questions in Standard Arabic. Linguistics and Literature Studies, 1(4), 179-190.

Al-Touny, K. (2011). Question formation between the Minimalist Program and Optimality Theory. Unpublished MA Thesis, Ain Shams University, Cairo.

Bayer, J. (2015). Doubly-filled Comp, wh head-movement, and derivational economy. Representing Structure in Phonology and Syntax, eds. Marc van Oostendorp and Henk van Riemsdijk, 7-39. https://doi.org/10.1515/9781501502224-002

Carnie, A. (2002). Syntax: a generative introduction. Oxford: Blackwell.

Chang, L. L.-S. (1997). On Partial Wh-Movement. UCI Working Papers in Linguistics, 3, 27-50.

Cheng, L. (1997). "Partial” Wh-Movement. UCI Working Papers in Linguistics, 3, 27-50.

Cheng, L. (2000). Typology of Wh-movement. Oxford: Oxford University Press.

Chomsky, N. (1957). Syntactic Structures. The Hague: Moulton.

Chomsky, N. (1977). On Wh-movement. In P. Cuticover et al. (Eds.), Formal Sybtax. New York: Academic Press.

Chomsky, N. (1988). Generative Grammar. Studies in English linguistics and literature. Kyoto University of Foreign Studies.

Chomsky, N.(1995). The minimalist program. Cambridge, MA: MIT press.

Chomsky, N., \& Keyser, S. J. (1982). Some concepts and consequences of the theory of government and binding. MIT press.

Cole, P., \& Hermon, G. (1994). Is there LF Wh-movement? Linguistic inquiry, 25(2), 239-262.

Cook, V., \& Newson, M. (2014). Chomsky's universal grammar. John Wiley \& Sons.

Culicover, P. (1997). Prinicples and Parameters. An introduction to syntactic Theory. New York: Oxford University Press.

Dayal, V. (2017). Does Hindi-Urdu Have Feature-Driven Wh-Movement to Spec, vP? Linguistic Inquiry, 48(1), 159-172. https://doi.org/10.1162/LING_a_00238

Fakih, A. H. A. (2015). Wh-questions in Hodeidi Arabic: a phase-based approach. Theory and Practice in Language Studies, 5(4), 773. https://doi.org/10.17507/tpls.0504.13

Givón, T. (2001). Syntax: an introduction (Vol. 1). John Benjamins Publishing.

Hartmann, J. M. (2016). Wh-movement and the small clause analyses of the English there-construction. Institut für Deutsche Sprache, Bibliothek.

Horrocks, G., \& Stavrou, M. (1987). Bounding theory and Greek syntax: evidence for Wh-movement in NP. Journal of Linguistics, 23(1), 79-108. https://doi.org/10.1017/S002222670001104X

Johnson, D., \& Lappin, S. (1997). A critique of the Minimalist Program. Linguistics and Philosophy, 20(3), 273-333. https://doi.org/10.1023/A:1005328611460

Kim, J. B., \& Sells, P. (2008). English syntax: An introduction. CSLI publications.

Lasnik, H., \& Urragereka, J. (1988). A course in GB Syntx. Cambridge, Mass: MIT Press.

Malhotra, S. (2009). Intervention Effects and Wh-movement. University of Pennsylvania Working Papers in Linguistics, 15(1), 16.

Manetta, E. (2010). Wh-expletives in Hindi-Urdu: the vP phase. Linguistic Inquiry, 4l(1), 1-34. https://doi.org/10.1162/ling.2010.41.1.1

McCloskey, J. (2000). Quantifier float and Wh-movement in an Irish English. Linguistic inquiry, 31(1), 57-84. https://doi.org/10.1162/002438900554299

Miller, J. (2016). Introduction to English Syntax. Edinburgh University Press.

Mowarin, M., \& Oduaran, A. (2014). A Contrastive Inquiry into Wh-Interrogatives in English and Nigerian Pidgin. English Linguistics Research, 3(2), 90. https://doi.org/10.5430/elr.v3n2p90 
Radford, A. (1997). Syntax: A Minimalist Introduction. Cambridge University Press. https://doi.org/10.1017/CBO9781139166898

Radford, A. (2004). English syntax: An introduction. Cambridge University Press. https://doi.org/10.1017/CBO9780511841675

Rivero, M. L. (1978). Topicalization and wh movement in Spanish. Linguistic Inquiry, 9(3), 513-517.

Seuren, P. A. (2004). Chomsky's minimalism. Oxford University Press.

Simpson, A., \& Bhattacharya, T. (2003). Obligatory overt Wh-movement in a Wh-in-situ language. Linguistic Inquiry, 34(1), 127-142. https://doi.org/10.1162/002438903763255940

Toosarvandani, M. (2008). Wh-movement and the syntax of sluicing. Journal of Linguistics, 44(3), 677-722.

Wahba, W. A. F. B. (1992). LF movement in Iraqi Arabic. In Logical structure and linguistic structure (pp. 253-276). Dordrecht: Springer. https://doi.org/10.1007/978-94-011-3472-9_9

Yeo, W. N. (2010). Unifying optional wh-movement. Doctoral dissertation, University of York.

Zeljko, B. (1999). On Multiple Wh-Fronting. Linguistic Inquiry, 33, 351-383.

\section{Copyrights}

Copyright for this article is retained by the author, with first publication rights granted to the journal.

This is an open-access article distributed under the terms and conditions of the Creative Commons Attribution license (http://creativecommons.org/licenses/by/4.0/). 